\section{Deterioration of Down House}

SIR - You have given a misleading impression of the involvement of the Royal College of Surgeons (RCS) in Down House, Charles Darwin's home (Nature 377, 90; 1995).

You fail to mention a number of important points. Following the death of Darwin's widow in 1896 and until the 1920 s, the family permitted the use of Down House as a school. Its future was a constant problem and it was eventually sold in 1929 to Sir George Buckston Browne who entrusted its care as a national memorial to the British Association for the Advancement of Science. The association maintained the property for many years, but found the running costs insupportable and, in 1953, the property was offered to the RCS.

Since then, the college has spent several hundred thousand pounds to maintain the house while striving with limited funds to fulfil its primary responsibilities in the professional fields of research, education and the maintenance of surgical standards. The National Trust was approached many years ago with a view to taking over Down House but declined. Three years ago, the Natural History Museum agreed to take it over on a 99-year lease and set about raising the funds necessary to restore it and up-date its facilities for visitors. It has failed to do so and a very substantial shortfall on its target is now, I understand, being sought from the National Lottery Heritage Fund. I would add that, over the past three years, there has been a visible deterioration in the external condition of the property.

Your allegation that "the rot set in" following the transfer of this property to the RCS is incorrect.

Rodney Sweetnam

(President)

Royal College of Surgeons of England, 35-43 Lincoln's Inn Fields,

London WC2A 3PN, UK

Contributions to the Down House Appeal may be addressed c/o Natural History Museum, London SW7 5BD.

\section{Contamination}

SIR - In response to the contamination of a researcher at the Massachusetts Institute of Technology (MIT)'s cancer laboratory (Nature 377, 563; 1995), the US Nuclear Regulatory Commission (NRC) has despatched an Incident Investigation Team to the facility. As part of its investigation, NRC will prepare an incident chronology; identify the source and nature of the phosphorus-32; project actual and potential dose consequences; evaluate the licensee's event reporting and response to the incident; investigate potential wrongdoing at the laboratory; and determine whether the NRC's regulatory procedures and activities preceding the event may have contributed to it.

The NRC has also sent a letter to David J. Litster, MIT's vice-president and dean for research, requiring that no later than 24 October certain steps be taken, ensuring among other things that security over radioisotopes is adequate to provide reasonable assurance against another such incident. Meanwhile, the NRC investigation of the contamination event that occurred in late June at the National Institutes of Health in Bethesda, Maryland, is continuing. The NRC does not, by the way, dispute the pregnant researcher's contention that she received a higher dose of P-32 than 26 other researchers contaminated at the laboratory.

\section{Victor Dricks}

US Nuclear Regulatory Commission, Office of Public Affairs, Region I,

475 Allendale Road,

King of Prussia, Pennsylvania 19401, USA

\section{Good manners}

SIR - The commentary by John Maddox on "Restoring good manners in research" (Nature 376, 113; 1995) may have been fitting for his address to a gathering of science editors, but it was wide of the mark as regards a description of the real crisis in the research community. While we should not accept increasingly frequent "bad manners" in publishing, I do not agree that academic institutions and grantmaking agencies have primary responsibility to ensure against these unfortunate activities. As in other such institutions, faculty at this university submit thousands of manuscripts each year. As the chief institutional research officer, can I ensure that the bibliography of each is accurate, not self-inflated, or appropriately inclusive of others? Clearly not. Institutions and agencies cannot and should not get into the business of censorship.

Most importantly, these matters should not distract us from more fundamental problems - a shocking increase in the number of cases involving significant alterations of data to suit one's preconceptions, misappropriation of scientific information for commercial gain, falsified effort or outright fabrication of data. In recent years, I have witnessed wholesale and egregious dishonesty in research, a different situation from the 'old days', and, I hasten to add, a picture that is not unique to this university. It is research misconduct of this type where academic institutions and agencies must take primary responsibility for establishing limits of acceptable research behaviour with comprehensive policies as well as mechanisms to ensure penalties for those who violate them.

Richard K. Koehn

210 Park Building,

University of Utah,

Salt Lake City, Utah 84112, USA

\section{HIV and AIDS}

SIR - The recent study of Darby and colleagues ${ }^{1}$ provides a direct link between infection with HIV and increased mortality due to AIDS in British haemophilia patients. Using a different approach, our group has studied the incidence of AIDS in the Sydney blood transfusion population (all infected before the introduction of screening for HIV in 1985) and found a direct association between the HIV antibody status of the donor and the incidence of AIDS in recipients ${ }^{2}$.

A successful donor/recipient Lookback Programme initiated by the New South Wales Red Cross Blood Transfusion Service in 1986 has identified specific HIVpositive donors for 101 out of a total of 132 HIV-positive blood transfusion recipients. In cases where the donor was identified only because a recipient became HIV-positive or developed AIDS, the first case of AIDS was excluded to remove selection bias. Excluding such cases, 66 blood transfusion recipients were traced of whom 40 have developed AIDS. In 1988 a parallel investigation aimed at finding blood transfusion-related cases was begun, and 7,000 recipients were tested of whom 10 were found to have AIDS. When these two groups are compared, the relative risk of AIDS associated with receiving blood known to be HIV-positive from tracing, is 424 (95\% confidence interval 342-526, $P<0.00001$ )(ref. 2).

Although the study of Darby et al. provides more impressive data in terms of sheer numbers, our transfusion study is unique in that (1) we have information on the health status of the donors and recipients, (2) we can link specific donors and recipients and (3) dates of infection are documented.

Collectively, our study ${ }^{2}$ and that of Darby et al. provide important and persuasive evidence directly linking HIV-antibody positivity with progression to AIDS.

John S. Sullivan

Jennifer C. Learmont

Andrew F. Geczy

Wayne Dyer

NSW Red Cross Blood

Transfusion Service,

153 Clarence Street,

Sydney, NSW 2000, Australia

1. Darby, S. et al. Nature 377, 79-82 (1995).

2. Sullivan, J. et al. AIDS Res. hum. Retrovir. 11 $1147-1148$ (1995). 